\title{
MRSA: A Challenge to Norwegian Nursing Home Personnel
}

\author{
M. Thorstad, ${ }^{1}$ I. Sie, ${ }^{1}$ and B. M. Andersen ${ }^{1,2}$ \\ ${ }^{1}$ Diakonova University College, 0166 Oslo, Norway \\ ${ }^{2}$ Department of Hospital Infections, Oslo University Hospital_Ullevål, 0407 Oslo, Norway
}

Correspondence should be addressed to B. M. Andersen, bjorgmarit.andersen@ulleval.no

Received 12 April 2011; Revised 15 June 2011; Accepted 17 July 2011

Academic Editor: Dinesh Mondal

Copyright ( 92011 M. Thorstad et al. This is an open access article distributed under the Creative Commons Attribution License, which permits unrestricted use, distribution, and reproduction in any medium, provided the original work is properly cited.

\begin{abstract}
In Norway, methicillin-resistant Staphylococcus aureus (MRSA) is increasing in primary healthcare, associated with imported cases and outbreaks in long-term care. According to Norwegian national guidelines, MRSA-exposed healthcare workers (HCWs) and patients are tested. Carriage of MRSA leads to exclusion from work in healthcare institutions. In this study, 388 staff members in 42 nursing homes in Oslo County responded to questions about personal experience with MRSA and of own attitudes to challenges associated with the control and treatment of MRSA patients. Half (52\%) of the nursing staff were concerned of becoming infected with MRSA and the consequences of this would be for own social life, family, economy, and work restriction. The concern was associated with risk factors like old buildings not suitable for modern infection control work, low staffing rate ( $70 \%$ without specific training in healthcare and $32 \%$ without formal healthcare education), defective cleaning and decolonization, and lack of formal routines and capacity for isolation of MRSA patients. Since the Norwegian MRSA guideline permits patients with persistent MRSA infections to move freely around in nursing homes, the anxiety of the staff to become infected and excluded from job was real.
\end{abstract}

\section{Introduction}

Nearly $1 \%$ of the Norwegian population live in nursing home with complex medical problems, high age (median 84 years), and need of assistance for daily living ( $>95 \%)$ [1-5]. Healthcare-associated infections (HAIs) are registered in $7 \%$ of these patients, $1 \%$ higher than in Norwegian hospitals, and the consequences are severe [6-8]. The Norwegian Infection Control Act demands written infection control programmes in nursing homes $[5,9,10]$.

In spite of international guidelines for infection prevention and control, nursing homes in Europe and USA may have large reservoirs of MRSA, affecting patients and staff, and resulting in persistent carriage [11-19]. Colonised cases may spread MRSA in the environment and via air [19-24]. The index person is often a staff member who may transmit MRSA via hands [21-24].

MRSA is still increasing in Norway, especially in the primary health care, associated with imported cases and outbreaks in long-term care, affecting both patients and personnel [25-27] (Figure 1). In the Oslo County, 10\% of all MRSA cases were healthcare personnel [26]. The outbreaks in nursing homes were associated with old buildings, insufficient isolation procedures and a less strict MRSA policy, failed eradication attempts, dement patients walking around, staff working part time at several institutions at the same time, overcrowding and mixture of patients, and lack of formal healthcare education $[5,10,25-27]$.

The Norwegian MRSA Control Guideline recommends testing of HCW exposed to MRSA [28]. Carriers are excluded from healthcare-related work until negative [28]. On the other hand, persistent carriers among the patients may move freely in the nursing home without any restrictions, and thereby expose personnel and other patients for MRSA [26-28]. The present study describes the staff's personal experience and attitudes to challenges in nursing homes, associated with the control and treatment of MRSA patients.

\section{Materials and Methods}

2.1. Nursing Homes. Forty two of 55 nursing homes in Oslo City participated, including 3350 beds with a mean of 102 beds per institution. They were divided into units of 10-25 patients, providing 24 hours care $[5,10]$. Leaders and sisters 


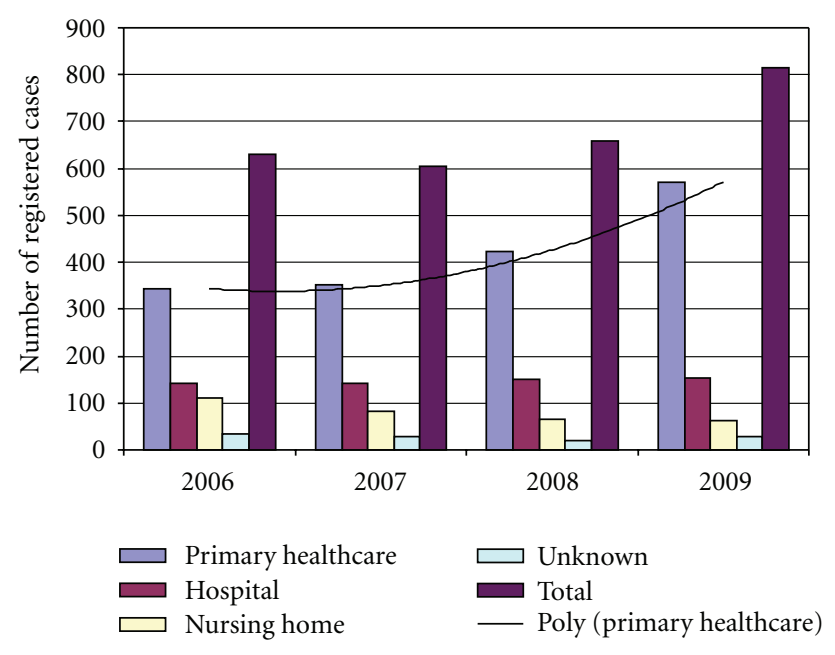

Figure 1: Development of MRSA (all cases) in Norway 2006-2009.

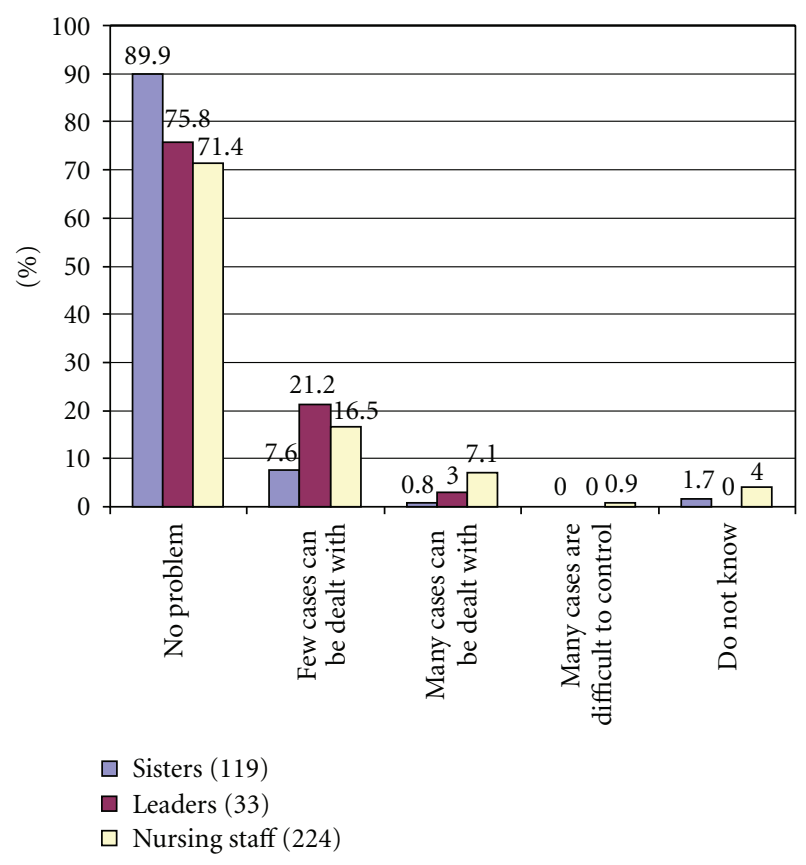

FIgURE 2: The size of the MRSA problem at your ward.

worked daytime, while nursing personnel worked on threedivided shift. Only $19 \%$ of the staff were nurses, $70 \%$ were without specific training in healthcare (students), and 32\% had no formal healthcare education at all.

2.2. The Staff Study and Questionnaire. Leaders and personnel were asked about infection control routines and knowledge and practice concerning MRSA [5]. The study was anonymous. This paper is based on data about infection control routines and the healthcare workers' personal feelings and attitude concerning challenges associated with the control and treatment of MRSA patients in nursing homes. The questions were about challenges like the quality of life of the MRSA-infected patient, the staffing situation, the extra need for cleaning, disinfection and decontamination, the functional standard of the buildings, the economic situation, and the need for information.

The nurse responsible for infection control distributed the questionnaire to the respondents [5]. In all, 528 questionnaires were delivered: 324 to nursing staff, 162 to sisters, and 42 to institution leaders.

The questions were ranged on a scale from 1 (no problem) to 5 (a very large problem).

Statistical data were analysed by SPSS 15.0 (SPSS Inc., Ill, USA).

\section{Results}

3.1. Respondents. Most nursing homes in Oslo (76.4\%) participated, caring for approximately 3350 patients in 126 wards, with mean 26 beds in each. The rate of responding was $73.5 \%$ (388/528). The 388 respondents were 229 nursing staff (nurses and assistant nurses), 126 sisters, and 33 institutional managers [5]. The nursing staff was $90 \%$ women, mean age 41 years, and mean time in work position 7.4 years. All had a work position of $50 \%$ or more. $18 \%$ worked part time at several other institutions. The sisters were mostly women $(87 \%)$, with mean age 46 years and mean time in work position 7 years. Among the 33 institution managers, 73\% were women. The mean age was 50 years.

3.2. Nursing Home Standard. Most nursing homes were old buildings: the oldest from 1860 and the newest from 2001. Half (52\%) of the buildings were estimated unsuitable for modern care of patients. The 3350 beds were in 2764 single rooms $(83 \%)$ and $586(17 \%)$ double rooms. Bathrooms were usually common for two or more residents. There was no isolation facility in the 42 institutions.

3.3. Earlier Experience with MRSA Cases. In all, $17 \%$ of the sisters had experienced at least one MRSA case at their unit during the last year. MRSA caused usually no problem (Figure 2). Only $7 \%$ of the nursing staff, $3 \%$ of the sisters, and $0.8 \%$ of the managers informed that they had many MRSA cases, but still the problem could be controlled.

3.4. The Staff's Concern of Becoming a Carrier. Half (52\%) of the nursing staff was worried of being infected or colonised with MRSA and about consequences for their social life, family, and work situation (Table 1). One of the respondents answered: "the consequences of becoming a carrier of MRSA as a HCW could be serious for my private economy and work quarantine. This is the reason why I try to get a new job outside the healthcare system." Six out of 18 sisters (33\%) who had experienced MRSA on own unit were concerned about the problem of MRSA, compared to 50 out of 96 (52.1\%) without this experience.

3.5. Challenges. The quality of life of an MRSA-infected patient was rated as a large challenge (Figure 3). The comments of the respondents were as follows: "It is a large ethical problem to isolate elderly people.", "MRSA is mostly a 


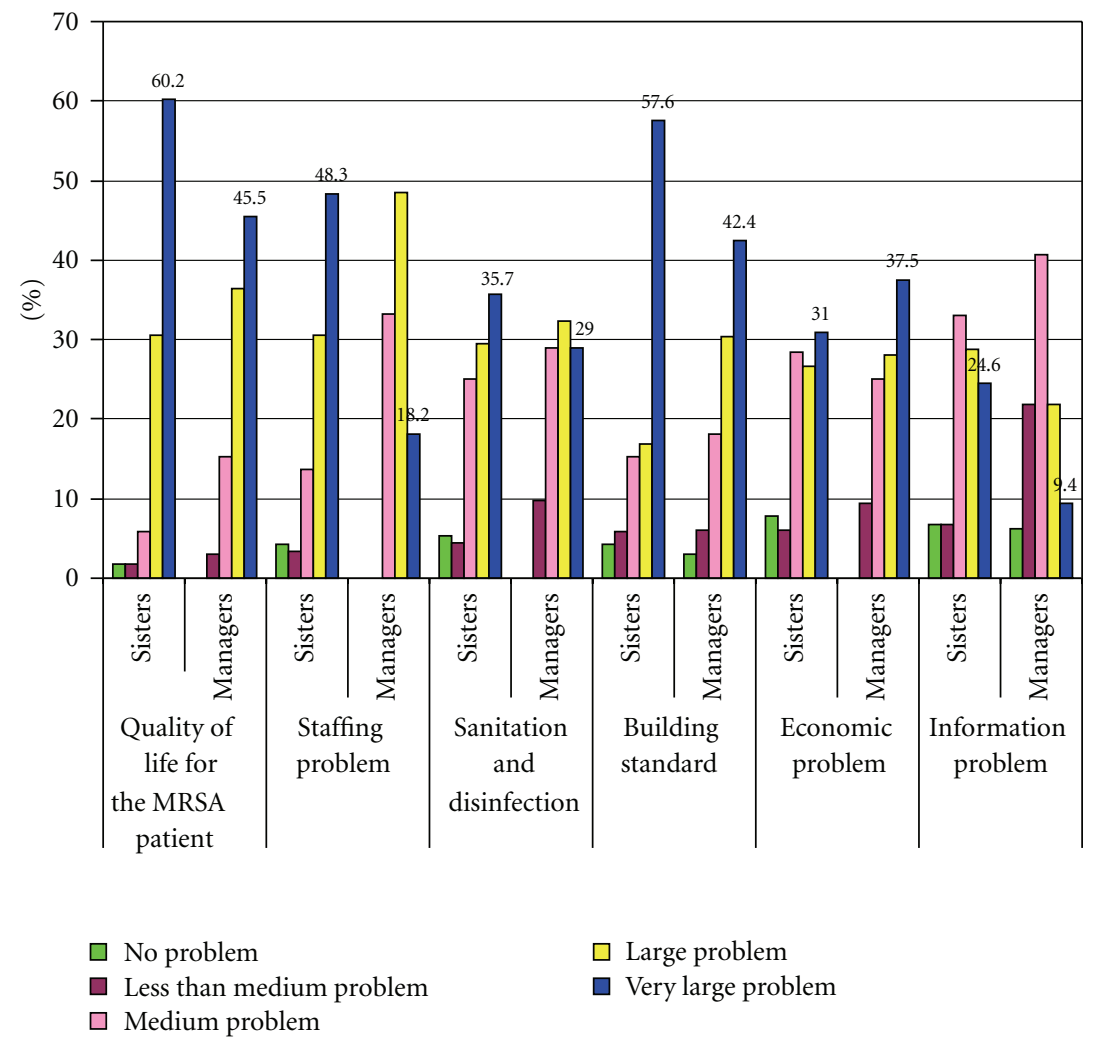

FIGURE 3: Nursing home problems associated with MRSA: quality of life, staffing, building standard, economy, information, sanitation, and disinfection.

serious problem for the infected person-himself", and "The MRSA-infected resident should be treated medically and socially with contact and stimulation as entitled to."

The staffing situation was estimated as a large challenge (Figure 3). The general staffing rate was low with $70 \%$ without specific training in healthcare and $32 \%$ without formal healthcare education.

The increased need of cleaning, disinfection, and sanitation of the environment and of the MRSA-infected patient seemed also to be a problem for the staff. One respondent described the situation as follows: "Low staffing rate, many non-healthcare personnel during weekends, few cleaning personnel and other problems."

The functional standard of the buildings was estimated as a large problem. A respondent commented the question: "The buildings are not constructed to take care of MRSA infection in the nursing home". Another respondent commented as follows: "Nursing homes have no isolation facilities and we do not have bathrooms for each patientso that is the largest challenge."

The economic situation concerning outbreak of MRSA seemed to be a medium to large problem, especially for the managers. The information to personnel, patients, relatives, hospital, and others was more important for the sisters than for the institution managers.

3.6. Ranging the Challenges during Outbreaks of MRSA. The quality of life of a patient with MRSA was ranged as the largest challenge (Table 2). The sisters then ranged successively lack of staffing (more staff for isolation work, etc.), nursing home standard (lack of isolation facility, sharing rooms and bathrooms), and increased need for cleaning, disinfections, and sanitation, as large problems, while economy and information was a medium large problem. The institutional managers were mostly concerned about the nursing home standard, followed by staffing, economy, and sanitation.

\section{Discussion}

Close living proximity, use of antibiotics, and the presence of pressure sores and indwelling devices make nursing home residents ideal for spreading MRSA [29]. MRSA-colonised residents are up to six times more likely to develop infection than noncolonised ones and so increase their risk of dying [29].

In this study, 388 staff members and managers in 42 nursing homes in Oslo County responded to questions about personal experience with MRSA and of attitudes to certain challenges associated with the control and treatment of MRSA in nursing homes. Problems were associated with old building standards not suitable for modern infection control work with lack of isolates, single rooms and bathrooms, a low rate of professional healthcare staffing and education in infection control work, and increased workload associated with cleaning, disinfection, and decolonizing. In addition, 
TABLE 1: Reasons for being concerned about MRSA among nurses.

\begin{tabular}{lcc}
\hline & $\begin{array}{c}\text { Yes/ } \\
\text { answered }\end{array}$ & $\begin{array}{c}\text { Yes } \\
\%\end{array}$ \\
\hline $\begin{array}{l}\text { Afraid of getting an } \\
\text { infection with MRSA } \\
\text { Afraid of becoming an }\end{array}$ & $77 / 84$ & 91 \\
$\begin{array}{l}\text { MRSA carrier } \\
\text { Afraid of loosing my job } \\
\text { because of MRSA carriage }\end{array}$ & $100 / 101$ & 99 \\
$\begin{array}{l}\text { Concerned about } \\
\text { consequences for my social } \\
\text { life if I become a carrier }\end{array}$ & $45 / 59$ & 76 \\
\hline
\end{tabular}

TABLE 2: Ranging the challenges associated with MRSA in nursing homes.

\begin{tabular}{|c|c|c|c|}
\hline \multicolumn{2}{|l|}{ Sisters } & \multicolumn{2}{|l|}{ Institution managers } \\
\hline $\begin{array}{l}\text { Quality of life for } \\
\text { the MRSA patient }\end{array}$ & $90,7 \%$ & $\begin{array}{l}\text { Quality of life for } \\
\text { the MRSA patient }\end{array}$ & $81,9 \%$ \\
\hline Personal staffing & $78,8 \%$ & $\begin{array}{l}\text { Nursing home } \\
\text { standard }\end{array}$ & $72,7 \%$ \\
\hline $\begin{array}{l}\text { Nursing home } \\
\text { standard }\end{array}$ & $74,5 \%$ & Personal staffing & $66,7 \%$ \\
\hline $\begin{array}{l}\text { Cleaning, } \\
\text { disinfection, and } \\
\text { sanitation }\end{array}$ & $65,2 \%$ & Economy & $65,6 \%$ \\
\hline Economy & $57,5 \%$ & $\begin{array}{l}\text { Cleaning, } \\
\text { disinfection, and } \\
\text { sanitation }\end{array}$ & $61,3 \%$ \\
\hline Information & $53,4 \%$ & Information & $31,3 \%$ \\
\hline
\end{tabular}

there was no isolation of persistent MRSA carriers, increasing the risk of transmission.

The weakness and limitation of the study was that the data were self-reported and could not be controlled by direct observation or additional questions [30]. Furthermore, our informants were selected, and personnel without health qualifications did not participate in this study.

Half of the nursing homes in Oslo County were not suitable for modern care of patients with no isolation facility in institutions caring for 3350 patients. Most patients shared bathrooms, and 20\% shared rooms. Lack of isolates increases transmission of MRSA which may persist on several body sites, are transmitted by personnel's hands, and dispersed into the environment and by air within 24 hours [19-21, $23,31,32$ ]. Single rooms with own bathroom should be the standard in nursing homes since sharing room increases the general risk of microbial transmission [33].

Untrained and uneducated personnel working in nursing homes increases the risk of spread of MRSA [34]. This was the situation for one-third of our staff. Part-time work at different health institutions may also increase the transmission risk. MRSA control guidelines for exposed patients and personnel were often not implemented [5].

The MRSA-infected patient was the largest challenge in nursing homes, since isolation may create an ethical problem. Therefore, infected residents should be decolonized at once and treated with contact and stimulation during the isolation period. The eradication method should be formalized and further studied to reach the best procedure for control. Still, some patients may become persistent carriers and should be taken especially care of [18, 25-27].

However, persistent carriers are, according to the Norwegian MRSA guideline, allowed to move freely in the nursing home, exposing unprotected patients and personnel for MRSA [28]. Exposed personnel are recommended to be tested for MRSA and if they are infected, they are excluded from healthcare work, also in nursing homes until documented MRSA negative [28]. Thus, this inconsequent guideline may lead to increased spread of infection among patients and personnel in nursing homes, increased work restrictions, and increased fear of being infected.

Half of the nursing staff in our study worried about being excluded from work because of MRSA carriage and the consequences of this would be for own social life, family and economy. The "twenty-first century lepers" because of MRSA carriage is already a problem and may be an even larger problem among personnel in healthcare $[35,36]$.

\section{Conclusion}

Half of the staff in nursing homes in Oslo County worried of being infected by MRSA. The reason could be that half of the nursing homes were not built for modern patient care. A low staffing rate and high number of uneducated personnel increased the risk of transmission, as did problems with environmental hygiene and eradication of the MRSA status. In addition, persistent carriers moving freely in the nursing home would increase the transmission risk.

To control MRSA and other resistant microbes, it is mandatory to enhance building standards, including isolates and single rooms with bathrooms. Furthermore, prevention of MRSA is dependent on a good quality care by welleducated staff not working part time at several institutions. The infected patient should be decolonized and taken care of in the best ethical way, without risk for transmission to unprotected patients, visitors, and staff. In the future, MRSA infection should be defined as a "consumer empowered, rare, and unacceptable event," also in nursing homes [37-40].

\section{References}

[1] B. M. Andersen and M. Rasch, "Hospital-acquired infections in Norwegian long-term-care institutions. A three-year survey of hospital-acquired infections and antibiotic treatment in nursing/residential homes, including 4500 residents in Oslo," Journal of Hospital Infection, vol. 46, no. 4, pp. 288-298, 2000.

[2] B. M. Andersen and M. Rasch, "Infections in nursing homes in Oslo," Tidsskrift for den Norske Laegeforening, vol. 122, no. 24, pp. 2371-2373, 2002.

[3] H. M. Eriksen, P. Elstrøm, S. Harthug, and P. E. Akselsen, "Infection control in health institutions for elderly," Tidsskrift for den Norske Laegeforening, vol. 125, no. 13-14, pp. 18351837, 2005.

[4] H. M. Eriksen, A. M. Koch, P. Elstrøm, R. M. Nilsen, S. Harthug, and P. Aavitsland, "Healthcare-associated infection among residents of long-term care facilities: a cohort and 
nested case-control study," Journal of Hospital Infection, vol. 65, no. 4, pp. 334-340, 2007.

[5] I. Sie, M. Thorstad, and B. M. Andersen, "Infection control and meticillin-resistant Staphylococcus aureus in nursing homes in Oslo," Journal of Hospital Infection, vol. 70, no. 3, pp. 235-240, 2008.

[6] B. M. Andersen, S. H. Ringertz, T. G. Petersen et al., "A threeyear survey of nosocomial and community-acquired infections, antibiotic treatment and re-hospitalization in a Norwegian health region," Journal of Hospital Infection, vol. 44, no. 3, pp. 214-223, 2000.

[7] B. M. Andersen, M. Rasch, K. Hochlin, T. Tollefsen, and L. Sandvik, "Hospital-acquired infections before and after healthcare reorganization in a tertiary university hospital in Norway," Journal of Public Health, vol. 31, no. 1, pp. 98-104, 2009.

[8] A. M. Koch, H. M. Eriksen, P. Elstrøm, P. Aavitsland, and S. Harthug, "Severe consequences of healthcare-associated infections among residents of nursing homes: a cohort study," Journal of Hospital Infection, vol. 71, no. 3, pp. 269-274, 2009.

[9] Norwegian Department of Health and Welfare, Communicable Disease Control Act. 1994 no. 55 Om vern mot smittsomme sykdommer, Forskrift om smittevern i helsetjenesten. 2005.

[10] I. Sie, M. Thorstad, and B. M. Andersen, "Infection control and hand hygiene in nursing homes in Oslo," Tidsskrift for den Norske Laegeforening, vol. 128, no. 13, pp. 1528-1530, 2008.

[11] P. W. Smith, G. Bennett, S. Bradley et al., "SHEA/APIC guideline: infection prevention and control in the long-term care facility," Infection Control and Hospital Epidemiology, vol. 29, no. 9, pp. 785-814, 2008.

[12] B. Barr, M. H. Wilcox, A. Brady, B. Darby, and D. Tompkins, "Prevalence of methicillin-resistant Staphylococcus aureus colonization among older residents of care homes in the United Kingdom," Infection Control and Hospital Epidemiology, vol. 28, no. 7, pp. 853-859, 2007.

[13] N. D. Stone, D. R. Lewis, H. K. Lowery et al., "Importance of bacterial burden among methicillin-resistant Staphylococcus aureus carriers in a long-term care facility," Infection Control and Hospital Epidemiology, vol. 29, no. 2, pp. 143-148, 2008.

[14] L. Mody, C. A. Kauffman, S. Donabedian, M. Zervos, and S. F. Bradley, "Epidemiology of Staphylococcus aureus colonization in nursing home residents," Clinical Infectious Diseases, vol. 46, no. 9, pp. 1368-1373, 2008.

[15] P. Brugnaro, U. Fedeli, G. Pellizzer et al., "Clustering and risk factors of methicillin-resistant Staphylococcus aureus carriage in two italian long-term care facilities," Infection, vol. 37, no. 3, pp. 216-221, 2009.

[16] M. Garazi, B. Edwards, D. Caccavale, C. Auerbach, and G. Wolf-Klein, "Nursing homes as reservoirs of MRSA: myth or reality?" Journal of the American Medical Directors Association, vol. 10, no. 6, pp. 414-418, 2009.

[17] O. Denis, B. Jans, A. Deplano et al., "Epidemiology of methicillin-resistant Staphylococcus aureus (MRSA) among residents of nursing homes in Belgium," Journal of Antimicrobial Chemotherapy, vol. 64, no. 6, pp. 1299-1306, 2009.

[18] A. Manzur and F. Gudiol, "Methicillin-resistant Staphylococcus aureus in long-term-care facilities," Clinical Microbiology and Infection, vol. 15, no. 7, pp. 26-30, 2009.

[19] S. Chang, A. K. Sethi, U. Stiefel, J. L. Cadnum, and C. J. Donskey, "Occurrence of skin and environmental contamination with methicillin-resistant Staphylococcus aureus before results of polymerase chain reaction at hospital admission become available," Infection Control and Hospital Epidemiology, vol. 31, no. 6, pp. 607-612, 2010.
[20] J. F. Gehanno, A. Louvel, M. Nouvellon, J.-F. Caillard, and M. Pestel-Caron, "Aerial dispersal of meticillin-resistant Staphylococcus aureus in hospital rooms by infected or colonised patients," Journal of Hospital Infection, vol. 71, no. 3, pp. 256-262, 2009.

[21] H. A. Ludlam, R. L. Swayne, A. M. Kearns et al., "Evidence from a UK teaching hospital that MRSA is primarily transmitted by the hands of healthcare workers," Journal of Hospital Infection, vol. 74, no. 3, pp. 296-298, 2010.

[22] E. Creamer, S. Dorrian, A. Dolan et al., "When are the hands of healthcare workers positive for meticillin-resistant Staphylococcus aureus?" Journal of Hospital Infection, vol. 75, no. 2, pp. 107-111, 2010.

[23] E. S. Yang, J. Tan, S. Eells, G. Rieg, G. Tagudar, and L. G. Miller, "Body site colonization in patients with communityassociated methicillin-resistant Staphylococcus aureus and other types of $S$ aureus skin infections," Clinical Microbiology and Infection, vol. 16, no. 5, pp. 425-431, 2010.

[24] W. C. Albrich and S. Harbarth, "Health-care workers: source, vector, or victim of MRSA?" The Lancet Infectious Diseases, vol. 8, no. 5, pp. 289-301, 2008.

[25] K. W. Larssen, T. Jacobsen, K. Bergh, P. Tvete, E. Kvello, and O. Scheel, "Outbreak of methicillin-resistant Staphylococcus aureus in two nursing homes in Central Norway," Journal of Hospital Infection, vol. 60, no. 4, pp. 312-316, 2005.

[26] B. M. Andersen, M. Rasch, and G. Syversen, "Is an increase of MRSA in Oslo, Norway, associated with changed infection control policy?" Journal of Infection, vol. 55, no. 6, pp. 531-538, 2007.

[27] H. F. L. van der Werff, T. W. Steen, K. M. Garder et al., "Et utbrudd av MRSA i et sykehjem i Oslo," Tidsskrift for den Norske Laegeforening, vol. 128, no. 23, pp. 2734-2737, 2008.

[28] National Guideline for Preventing Infections with MRSA in Healthcare. MRSA-Veilederen, Norwegian Institute of Public Health, Oslo, Norway, 2008.

[29] C. M. Hughes, M. B. H. Smith, and M. M. Tunney, "Infection control strategies for preventing the transmission of meticillin-resistant Staphylococcus aureus (MRSA) in nursing homes for older people," Cochrane Database of Systematic Reviews, no. 1, article CD006354, 2008.

[30] E. A. Jenner, B. C. Fletcher, P. Watson, F. A. Jones, L. Miller, and G. M. Scott, "Discrepancy between self-reported and observed hand hygiene behaviour in healthcare professionals," Journal of Hospital Infection, vol. 63, no. 4, pp. 418-422, 2006.

[31] A. Clements, K. Halton, N. Graves et al., "Overcrowding and understaffing in modern health-care systems: key determinants in meticillin-resistant Staphylococcus aureus transmission," The Lancet Infectious Diseases, vol. 8, no. 7, pp. 427-434, 2008.

[32] B. M. Andersen, T. Tollefsen, B. Seljordslia et al., "Rapid MRSA test in exposed persons: costs and savings in hospitals," Journal of Infection, vol. 60, no. 4, pp. 293-299, 2010.

[33] M. Hamel, D. Zoutman, and C. O'Callaghan, "Exposure to hospital roommates as a risk factor for health care-associated infection," American Journal of Infection Control, vol. 38, no. 3 , pp. 173-181, 2010.

[34] N. S. Baldwin, D. F. Gilpin, M. M. Tunney et al., "Cluster randomised controlled trial of an infection control education and training intervention programme focusing on meticillinresistant Staphylococcus aureus in nursing homes for older people," Journal of Hospital Infection, vol. 76, no. 1, pp. 36-41, 2010. 
[35] K. L. Mozzillo, N. Ortiz, and L. G. Miller, "Patients with meticillin-resistant Staphylococcus aureus infection: twentyfirst century lepers," Journal of Hospital Infection, vol. 75, no. 2, pp. 132-134, 2010.

[36] M. Lindberg, M. Carlsson, M. Högman, and B. Skytt, "Suffering from meticillin-resistant Staphylococcus aureus: experiences and understandings of colonization," Journal of Hospital Infection, vol. 73, no. 3, pp. 271-277, 2009.

[37] M. J. Struelens and D. L. Monnet, "Prevention of methicillinresistant Staphylococcus aureus infection: is Europe winning the fight?" Infection Control and Hospital Epidemiology, vol. 31, no. 1, pp. S42-S44, 2010.

[38] M. L. Moro, B. Jans, B. Cookson, and J. Fabry, "The burden of healthcare-associated infections in European long-term care facilities," Infection Control and Hospital Epidemiology, vol. 31, no. 1, pp. S59-S62, 2010.

[39] J. L. Gerberding, "Healthcare epidemiology: past and future," Infection Control and Hospital Epidemiology, vol. 31, no. 1, pp. S73-S75, 2010.

[40] T. R. Frieden, "Maximizing infection prevention in the next decade: defining the unacceptable," Infection Control and Hospital Epidemiology, vol. 31, no. 1, pp. S1-S3, 2010. 


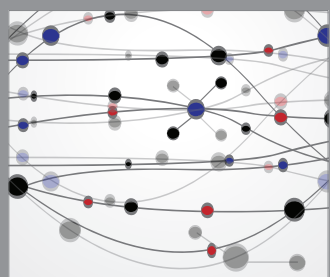

The Scientific World Journal
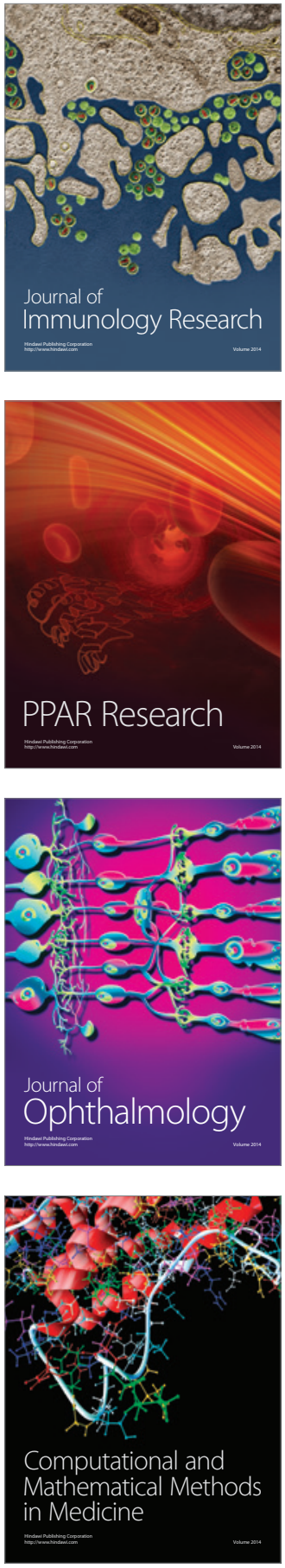

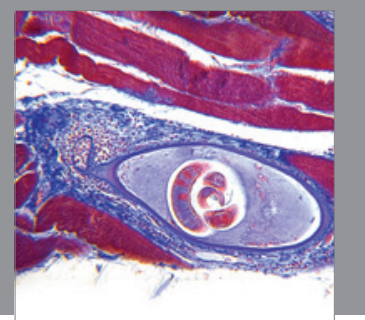

Gastroenterology

Research and Practice
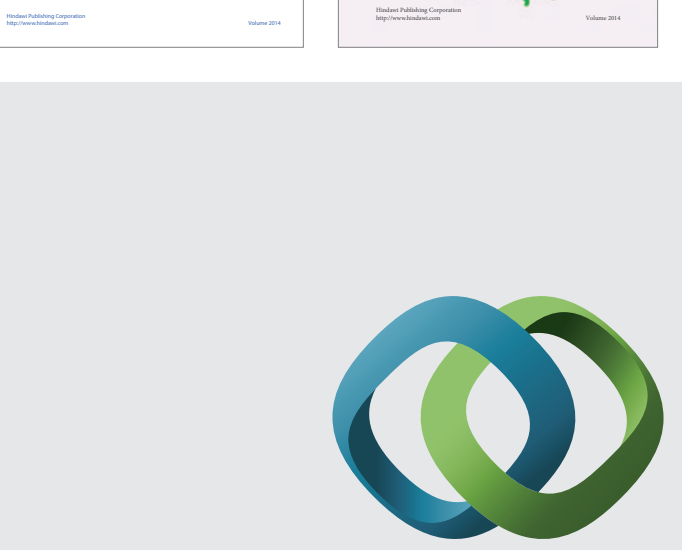

\section{Hindawi}

Submit your manuscripts at

http://www.hindawi.com
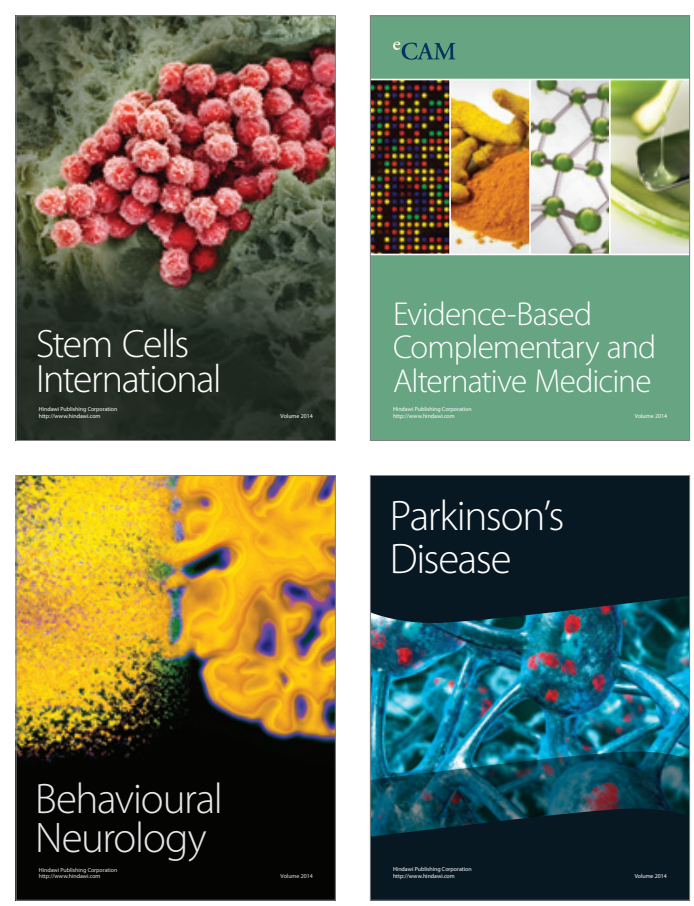

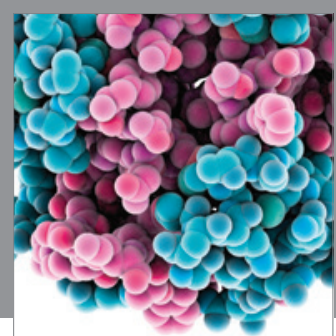

Journal of
Diabetes Research

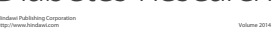

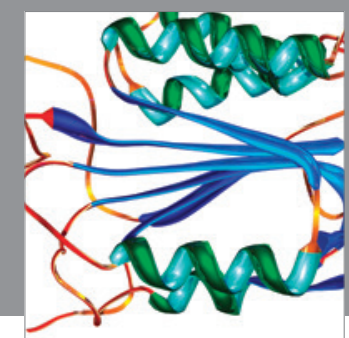

Disease Markers
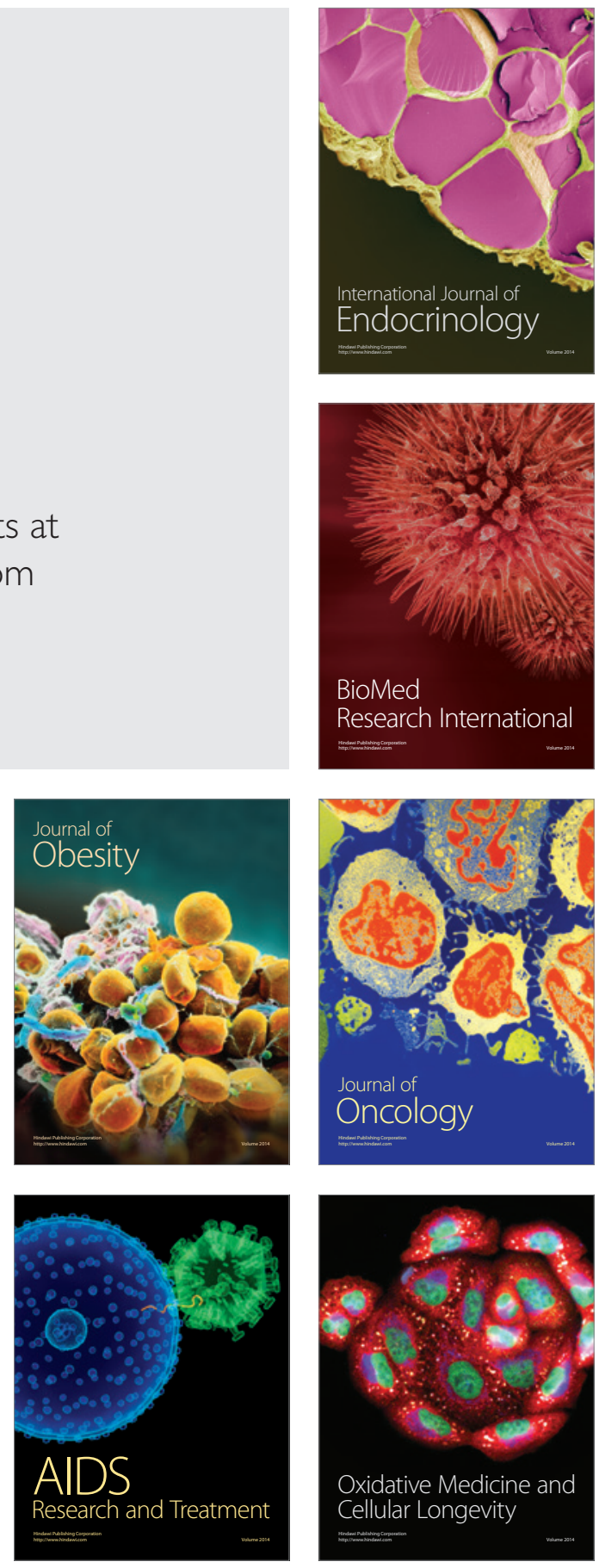